\title{
Effect of an Al(III) Complex on the Regio- and Stereoisomeric For- mation of Bicyclic Organic Carbonates
}

\author{
Cristina Maquilón, ${ }^{\S \ddagger}$ Bart Limburg, ${ }^{\S}$ Victor Laserna, ${ }^{\S}$ Diego Garay, ${ }^{\S}$ Joan González Fabra,${ }^{\S}$ Carles Bo, ${ }^{\S \ddagger}$ \\ Marta Martínez Belmonte, ${ }^{\S}$ Eduardo C. Escudero-Adán ${ }^{\S}$ and Arjan W. Kleij* ${ }^{\S \dagger}$ \\ $\S$ Institute of Chemical Research of Catalonia (ICIQ), Barcelona Institute of Science \& Technology (BIST), Av. Països Cata- \\ lans 16, 43007 - Tarragona, Spain \\ ${ }^{\dagger}$ Catalan Institute of Research and Advanced Studies (ICREA), Pg. Lluis Companys 23, 08010 - Barcelona, Spain \\ * Departament de Química Física i Inorgànica, Universitat Rovira i Virgili, Marcel-lí Domingo s/n, 43007 Tarragona, Spain \\ Supporting Information Placeholder
}

\begin{abstract}
Valorization of carbon dioxide into organic molecules using catalytic approaches has witnessed an upsurge in recent years. Here, the influence of an $\mathrm{Al}(\mathrm{III})$ aminotriphenolate complex on the regio- and stereo-chemical features of the coupling between carbon dioxide and a cyclic epoxy alcohol has been studied. Three distinct bicyclic carbonate products were produced from a single starting material depending on the catalytic conditions. The proposed carbonate configurations were examined by solution and solid phase techniques including NMR spectroscopic and X-ray crystallographic analyses. Control experiments combined with DFT calculations provide a rationale for the distinct catalytic manifolds observed in the presence and absence of the $\mathrm{Al}(\mathrm{III})$ complex.
\end{abstract}

\section{INTRODUCTION}

Contemporary research focusing on the use of carbon dioxide as a readily available carbon feedstock in organic synthesis $^{1-8}$ has a major focus on the discovery of new transformations ${ }^{9-14}$ while improving existing ones. ${ }^{15-19}$ Whereas the vast majority of the conversions that utilize $\mathrm{CO}_{2}$ as one of the substrates involve catalytic protocols that afford the final product in racemic form, recent work has shown an upsurge of more challenging, enantioselective or stereo-divergent transformations. ${ }^{20-25}$ Among the most common synthetic efforts, the ones that incorporate $\mathrm{CO}_{2}$ whilst preserving a high oxidation state of the carbon center originally present in the $\mathrm{C} 1$ reagent prevail. This is exemplified by the development of diverse organic transformations that result in functional compounds such as carboxylic acids, ${ }^{26-29}$ organic carbonates ${ }^{30-36}$ and carbamates. ${ }^{37-39}$

The area of cyclic carbonate synthesis has witnessed a spectacular growth over the last decade ${ }^{2,3,30-32}$ with a primary focus on the development of improved and more sustainable catalysts for the [3+2] cycloaddition of epoxides and $\mathrm{CO}_{2} \cdot{ }^{40-43}$ The (dia)stereoselective formation of more complex cyclic organic carbonates ${ }^{25,44,45}$ however, remains underdeveloped. It is generally assumed that the formation of a cyclic carbonate from epoxides and $\mathrm{CO}_{2}$ follows a typical three-step sequence involving epoxide ring opening induced by the (binary) catalyst, subsequent activation of the $\mathrm{CO}_{2}$ molecule by the intermediate alkoxide and termination through cyclization releasing the desired product. ${ }^{46-50}$ However, recent work from two laboratories has illustrated that certain catalysts ${ }^{51,52}$ or specific substrates ${ }^{53,54}$ may alter the reaction pathway, leading to regio- and stereomeric products.
Scheme 1. Previous Formation of Bicylic Carbonates (a) and Current Regio- and Diastereodivergent Synthesis (b)

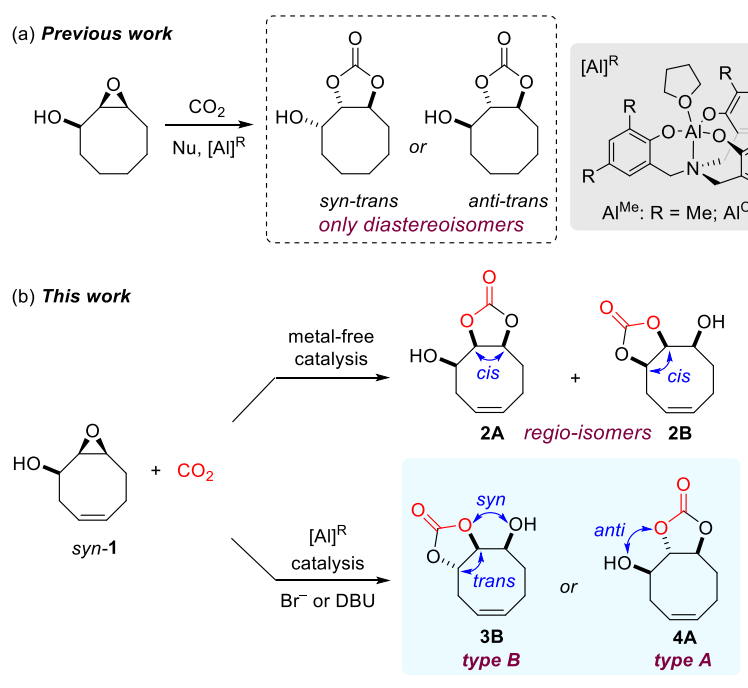

Recently we reported on a substrate-controlled conversion of cyclic epoxy alcohols with $\mathrm{CO}_{2} \cdot{ }^{25}$ Different stereoselective routes for cyclic carbonate formation could be triggered by a judicious choice of the catalyst components derived from an Al(III) based Lewis acid and an accompanying external nucleophile (Scheme 1a). We observed the formation of rare (syn/anti) trans-configured bicyclic carbonates. However, due to the symmetric nature of the rings, we were unable to unambiguously differentiate between regio-isomers that may be produced. These latter regioisomeric carbonates would be produced via conventional $[3+2]$ cycloaddition into the epoxide 
Table 1. Screening Conditions for the Coupling of Epoxy Alcohol (syn-1) and $\mathrm{CO}_{2}$ using Halide Salts as Catalysts. ${ }^{a}$

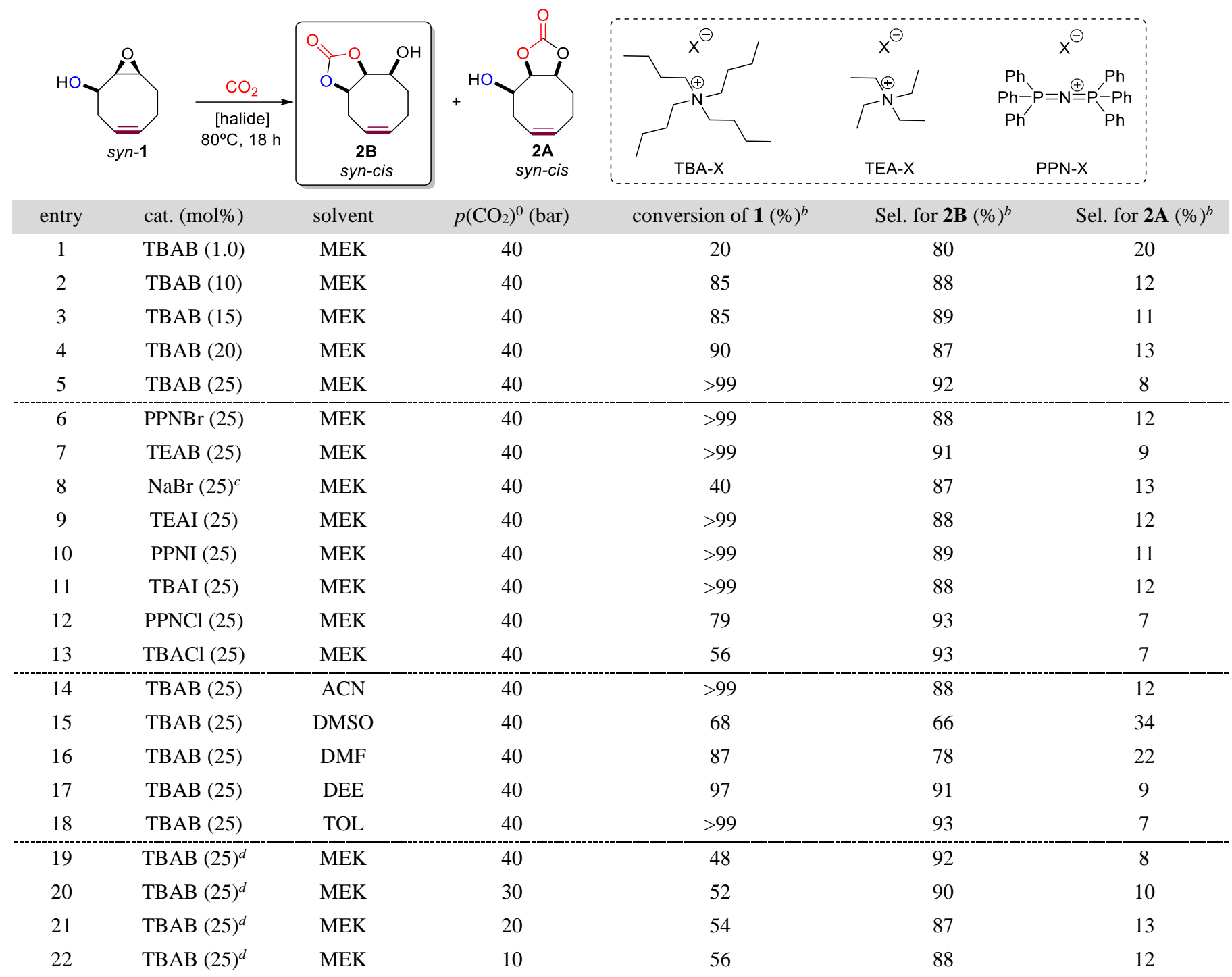

${ }^{a}$ Reaction conditions: $80^{\circ} \mathrm{C}, 18 \mathrm{~h}$, substrate $1(0.50 \mathrm{mmol}, 70 \mathrm{mg}, 2.5 \mathrm{M})$, MEK = methyl ethyl ketone. DEE stands for diethoxyethane. ${ }^{b}$ Based on ${ }^{1} \mathrm{H}$ NMR integration of the crude product taking only the starting material and carbonate products into account. Sel. $=$ selectivity. ${ }^{c}$ The reaction mixture was heterogeneous. ${ }^{d}$ Carried out in a different pressurized HTE system, see SI for details.

only (type A), or formed by substrate-controlled incorporation of the alcohol in the substrate (type B), see Scheme 1b. This result prompted us to consider other cyclic epoxy alcohol substrates that do not show this symmetry, by introduction of a different degree of rigidity in their backbone and to examine the influence on the regio- and stereoselective nature of the overall [3+2] cycloaddition reaction (Scheme 1b). In this work, we will demonstrate that introducing a symmetry-breaking element in the backbone of the cyclic epoxy alcohol substrate delivers new configurations that remained previously unnoticed. By using $\mathrm{Al}$ (III)-based catalysts, we are able to access two unexpected products, different from those produced using standard $\mathrm{Br}^{-}$-catalysis. Knowing the absolute configuration is of vital importance to design conversions that capitalize on the synthetic potential of readily available and ubiquitous epoxy alcohols delivering organic cyclic carbonates under high stereo- and/or regio-control. Such carbonates are valuable as is, or can be used as precursors to triols with absolute stereo-configuration. . $^{255}$ Notably, these protocols allow for the selective synthesis of 3 out of 8 possible isomeric products from a single starting material, and produces 2 additional isomers in minor amounts.

\section{RESULTS AND DISCUSSION}

Halide Catalyzed Carbonation. We began to investigate the conversion of epoxy alcohol syn-1 into bicyclic carbonates using a metal-free, halide-based catalyst and the results are gathered in Table 1. Based on previous work carried out by us in this area with other types of cyclic epoxy alcohols, ${ }^{25}$ the initial reactions conditions were provisionally set at $80^{\circ} \mathrm{C}$ and 40 bar initial $\mathrm{CO}_{2}$ pressure while using an $18 \mathrm{~h}$ reaction time. Tetrabutylammonium bromide (TBAB) was first scrutinized (Table 1 , entry 1 ) at a loading of $1 \mathrm{~mol} \%$ with respect to syn-1. Under these conditions, formation of cyclic carbonate products was rather sluggish and therefore the amount of TBAB was gradually increased (Table 1, entries 2-5) revealing eventually that a virtual full conversion of syn-1 could be achieved at a loading of $25 \mathrm{~mol} \%$ TBAB. Out of the products, we identified syn-cis $\mathbf{2 B}$ as major and syn-cis $\mathbf{2 A}$ as minor products in $92 \%$ 
to $8 \%$ selectivity, respectively. Interestingly, the selectivity seems to not depend on the type of nucleophilic catalyst (Table 1 entries 6-13), although lower conversions were obtained using poorly soluble salts $(\mathrm{NaBr}$, entry 8$)$, or chlorides (Table 1 entries 12-13). The lower potential of chloride-based nucleophiles in epoxide $/ \mathrm{CO}_{2}$ coupling reactions follows general trends typically noted in this area. ${ }^{56}$ The selectivity was neither perturbed by the $\mathrm{CO}_{2}$ pressure (Table 1, entries 19-22), and was only affected slightly by the choice of solvent (entries 14-18). In these cases, a lower selectivity goes accompanied by a lower conversion, and therefore MEK was selected as the solvent for further studies.
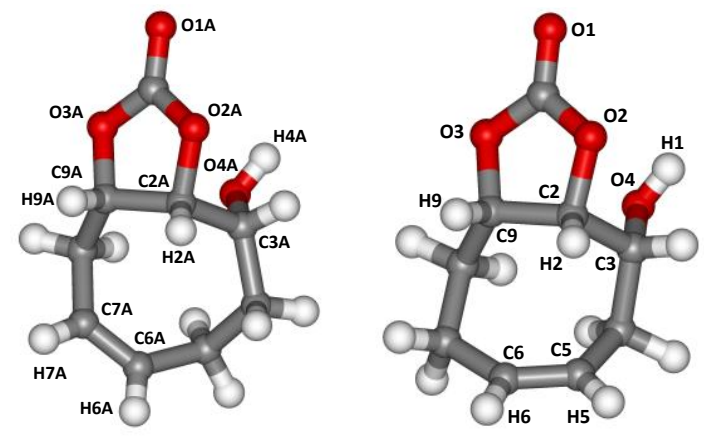

Figure 1. LEFT: X-ray molecular structure determined for syn-cis 2B (major isomer). Some selected pertinent bond lengths $(\AA)$ and dihedral angles $\left({ }^{\circ}\right)$ with esd's in parentheses: $\mathrm{C}(6 \mathrm{~A})-\mathrm{C}(7 \mathrm{~A})=$ 1.3323(8); $\mathrm{O}(2 \mathrm{~A})-\mathrm{C}(2 \mathrm{~A})-\mathrm{C}(9 \mathrm{~A})-\mathrm{O}(3 \mathrm{~A})=27.20(5), \mathrm{O}(2 \mathrm{~A})-\mathrm{C}(2 \mathrm{~A})-$ $\mathrm{C}(3 \mathrm{~A})-\mathrm{O}(4 \mathrm{~A})=-70.22(5)$. RIGHT: X-ray molecular structure determined for syn-cis $\mathbf{2 A}$ (minor isomer). Some selected pertinent bond lengths $(\AA)$ and dihedral angles $\left({ }^{\circ}\right)$ with esd's in parentheses: $\mathrm{C}(5)-\mathrm{C}(6)=1.3324(17), \mathrm{O}(2)-\mathrm{C}(2)-\mathrm{C}(9)-\mathrm{O}(3)=22.49(9), \mathrm{O}(2)-$ $\mathrm{C}(2)-\mathrm{C}(3)-\mathrm{O}(4)=-54.62(11)$.

In order to optimize the yield of syn-cis $\mathbf{2 B}$, reactions were then performed at a larger scale $(1 \mathrm{mmol})$ and at a lower concentration of syn-1 (1 M) while keeping most of the other reaction conditions constant. Some variation of the reaction temperature was applied $\left(60-80{ }^{\circ} \mathrm{C}\right.$; see Table S1 entries $1-3$ in the Supporting Information, SI) showing that the preparation of syn-cis $\mathbf{2 B}$ is best performed at $80{ }^{\circ} \mathrm{C}$ (entry 3) affording the desired product in a $76 \%$ NMR and $65 \%$ isolated yield after chromatographic purification. ${ }^{57}$ The afforded pure materials could be crystallized and examined in detail by X-ray crystallography (Figure 1). The crystallographic studies indisputably showed that two regio-isomeric cyclic carbonates $(\mathbf{2 A}$ and $\mathbf{2 B})$ had been formed having both a syn-cis configuration. Surprisingly, the major isomer turned out to be syn-cis $\mathbf{2 B}$, i.e. the carbonate product of type $\mathbf{B}$, contrary to what would be expected if a standard double inversion would have taken place. ${ }^{43,48,58}$

DFT Studies. The combined results collected in Table 1 seem to propose that the formation of syn-cis $\mathbf{2 B}$ is the result of an unknown manifold that should involve an overall double inversion pathway, different from the standard mechanism. In order to shed light on the formation of the regio-isomer syn-cis 2B, density functional theory (DFT) calculations were performed (see Figure 2); for further details see the Experimental section and Supporting Information, SI). In the presence of TBAB, syn-1 can be converted both via $\alpha$ - or $\beta$-attack of the bromide onto the epoxy alcohol. Moreover, we computed both stepwise and concerted processes, with the latter thus combining epoxide ring-opening and linear carbonate formation. The stepwise formation of syn-cis $\mathbf{2 A}$ via the $\beta$-attack has an energetic span $(\Delta \mathrm{E}$; relative to $s y n-\mathbf{1})$ of $22.6 \mathrm{kcal} / \mathrm{mol}$, whereas the $\alpha$-attack has a significantly lower $\Delta \mathrm{E}(18.7 \mathrm{kcal} / \mathrm{mol})$. The concerted pathways to the linear carbonate intermediates demonstrate that via initial $\beta$-attack the $\Delta \mathrm{E}$ is higher $(21.2 \mathrm{kcal} / \mathrm{mol})$ compared to the stepwise manifold, while the pathway from an $\alpha$-attack is favored even more $(\Delta \mathrm{E}=15.8 \mathrm{kcal} / \mathrm{mol})$. Therefore, the formation of syn-cis $\mathbf{2 A}$ is suggested to go through initial $\alpha$ attack of the bromide nucleophile. Importantly, the calculated energies involved in the formation of the respective intermediates and transition states shows that under the experimental conditions $\left(80^{\circ} \mathrm{C}, 40\right.$ bar $)$ these steps should be reversible.

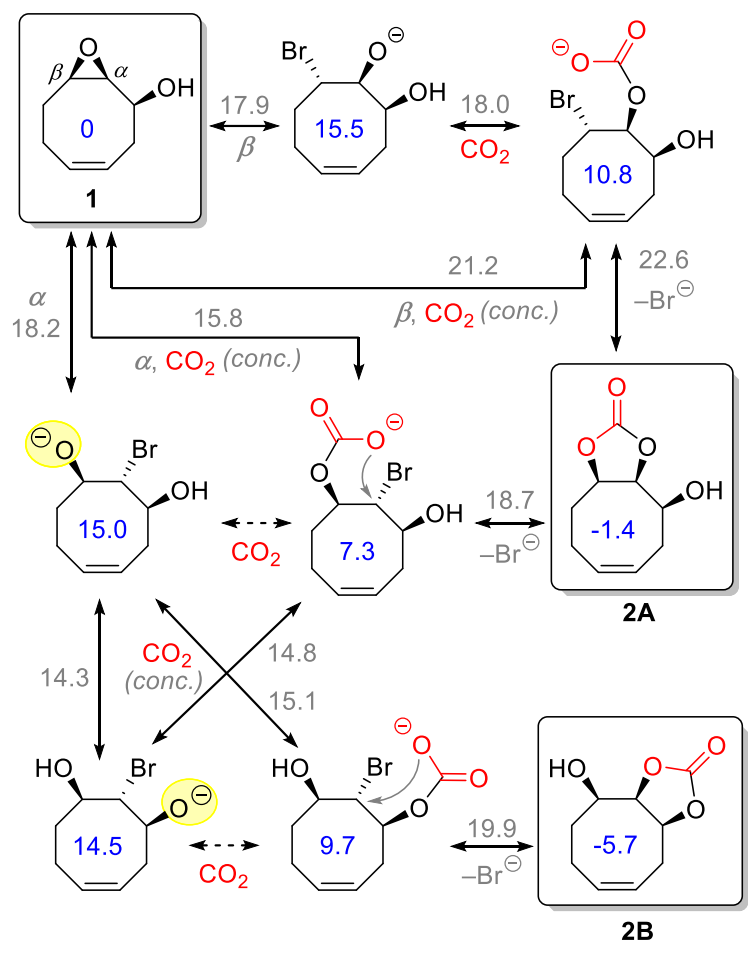

Figure 2. DFT computed pathways for the formation of $\mathbf{2 A}$ through step-wise and concerted (conc.) pathways via $\alpha$ - and $\beta$-attack of the bromide nucleophile. Interconversion of the alkoxide species formed after initial bromide-mediated ring-opening of syn-epoxy alcohol 1 through intramolecular proton transfer (highlighted in yellow) leads to product $\mathbf{2 B}$. The accompanying TBA cations are omitted for clarity in all manifolds. In blue, the Gibbs free energies (in $\mathrm{kcal} / \mathrm{mol}$ ) of the intermediates are given; the numbers in grey refer to the calculated Gibbs free energies of the corresponding transitions states. All energies are relative to the energy of $\mathbf{1}$.

The formation of product $\mathbf{2 B}$ cannot occur through a mechanism involving a $\beta$-attack, and we therefore explored possible pathways from the alkoxide produced after initial $\alpha$-attack of the bromide onto the epoxide unit in syn-1 (in Figure 2). This intermediate can isomerize through an intramolecular proton transfer (the oxygen anions involved are indicated in yellow) practically without barrier. The resultant alkoxide isomer can then lead to the formation of syn-cis $\mathbf{2 B}$ through an apparent barrierless $\mathrm{CO}_{2}$ activation and subsequent cyclization having a barrier of $19.9 \mathrm{kcal} / \mathrm{mol}$. Other routes leading to syn-cis 2 (see SI) via formation of an isomerized syn epoxy alcohol and subsequent stepwise/concerted ring-opening, $\mathrm{CO}_{2}$ activation and cyclization (including $\alpha$ - and $\beta$-pathways) were considered, but have energetic spans (slightly) above the one computed for the stepwise conversion of the isomerized alkoxide into $\mathbf{2 B}$. 
The free energy of the product $\mathbf{2 B}(-5.7 \mathrm{kcal} / \mathrm{mol})$ is substantially lower than that of $\mathbf{2 A}(-1.4 \mathrm{kcal} / \mathrm{mol}) . \mathbf{2 B}$ is therefore the expected thermodynamic product, given that there are no other thermodynamic wells in the scheme (i.e., all reactions are reversible at $80{ }^{\circ} \mathrm{C}$ ). Thus, the mechanistic DFT results align well with the experimental observation that $\mathbf{2 B}$ is the major product, and the final product ratio is therefore thermodynamically controlled. Microkinetic modeling was performed (see SI) showing a good fit with the experimental observations predicting a $95 \%$ selectivity for $\mathbf{2 B}$ ( $92 \%$ observed).

Table 2. Conversion of Syn-1 in the Presence of Al(III) Complexes $\mathrm{Al}^{\mathrm{Me}}$ or $\mathrm{Al}^{\mathrm{Cl}}$ and a Halide based Nucleophile. ${ }^{a}$

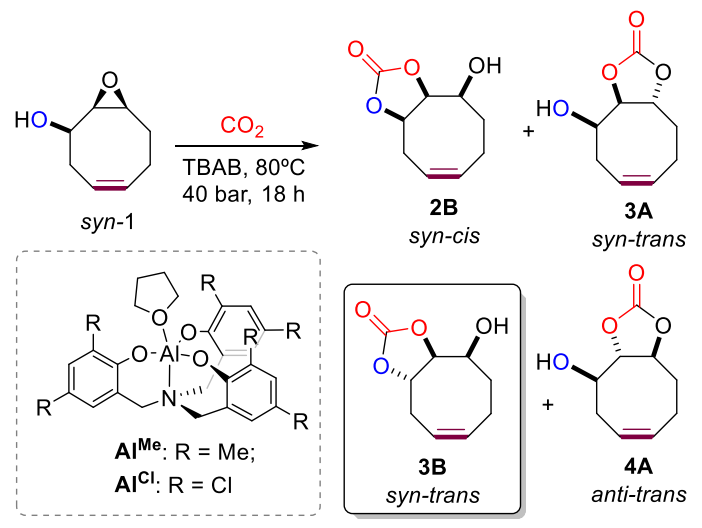

\begin{tabular}{|c|c|c|c|c|}
\hline entry & $\begin{array}{c}{[\mathrm{Al}]} \\
(\mathrm{mol} \%)\end{array}$ & $\begin{array}{l}\text { TBAB } \\
\text { mol\% }\end{array}$ & $\begin{array}{c}\text { Sel. }{ }^{b} \\
\text { 2B:3A:3B:4A } \\
(\%)\end{array}$ & $\begin{array}{c}\text { Yield } \\
\text { 3B }(\%)\end{array}$ \\
\hline 1 & $\mathbf{A l}^{\mathrm{Me}}(1.0)$ & 1.0 & $16: 22: 34: 28$ & n.d. \\
\hline 2 & $\mathbf{A} \mathbf{l}^{\mathbf{M e}}(1.0)$ & 10 & $27: 17: 38: 18$ & n.d. \\
\hline 3 & $\mathbf{A l}^{\mathbf{C l}}(1.0)$ & 2.5 & 0:15:74:11 & n.d. \\
\hline 4 & $\mathrm{Al}^{\mathrm{Cl}}(1.0)$ & 1.0 & $0: 6: 81: 16$ & n.d. \\
\hline 5 & $\mathrm{Al}^{\mathrm{Cl}}(5.0)$ & 5.0 & 4:6:90:0 & n.d. \\
\hline 6 & $\mathrm{Al}^{\mathrm{Cl}}(7.5)$ & 7.5 & 2:9:89:0 & n.d. \\
\hline 7 & $\mathbf{A l}^{\mathbf{C l}}(10)$ & 10 & $3: 6: 91: 0$ & n.d. \\
\hline $8^{c}$ & $\mathbf{A l}^{\mathbf{C l}}(5.0)$ & 5.0 & $7: 13: \mathbf{8 0}: 0$ & $42(29)^{d}$ \\
\hline $9^{\mathrm{ce}}$ & $\mathbf{A l}^{\mathbf{C l}}(5.0)$ & 5.0 & 2:6:92:0 & $33^{g}$ \\
\hline $10^{c f}$ & $\mathrm{Al}^{\mathrm{Cl}}(5.0)$ & 5.0 & 0:7:93:0 & $16^{g}$ \\
\hline
\end{tabular}

${ }^{a}$ Reaction conditions: $18 \mathrm{~h}, 80^{\circ} \mathrm{C}, 40$ bar $\mathrm{CO}_{2}$, syn-1 $(0.5 \mathrm{mmol}, 70$ $\mathrm{mg}, 2.5 \mathrm{M}$ ), TBAB (16 mg, $5.0 \mathrm{~mol} \%$ ), MEK. Conversion was $>99 \%$ in all cases. ${ }^{b}$ Based on ${ }^{1} \mathrm{H}$ NMR integration of the crude product; numbers refer to conversion into carbonates. ${ }^{c}$ Reactions were carried out in an autoclave equipped with a $20 \mathrm{~mL}$ Teflon insert, using syn-1 (1.0 mmol, $140 \mathrm{mg}, 1.0 \mathrm{M})$ and $\mathrm{Al}^{\mathrm{Cl}} / \mathrm{TBAB}(5.0$ mol\% each), $80{ }^{\circ} \mathrm{C}, 40$ bar, 24 h. ${ }^{d}$ Overall cyclic carbonate selectivity: 55\%. NMR yield for syn-trans $3 \mathrm{~B}$ was $42 \%$ using 1,3,5-trimethoxy-benzene as internal standard. In brackets the isolated yield of syn-trans $\mathbf{3 B}$ after column purification. ${ }^{e}$ Temperature: $70{ }^{\circ} \mathrm{C}$. ${ }_{\text {pCO2: }} 10$ bar. ${ }^{g} \mathrm{~A}$ different unidentified product is produced is large amounts. n.d. $=$ not determined.

Al-Catalyzed Formation of Syn-Trans 3B. With these reference data in hand, we continued to study the influence of the addition of $\mathrm{Al}(\mathrm{III})$ aminotriphenolate complexes $\mathbf{A l}^{\mathrm{Me}}$ and $\mathbf{A l}{ }^{\mathrm{Cl}}$ (Scheme 1) on the outcome of the cycloaddition of $\mathrm{CO}_{2}$ to epoxy alcohol syn-1 (Table 2). We decided to first use Al(III) complex $\mathbf{A l}^{\mathrm{Me}}$ in combination with TBAB starting with relatively low loadings of $1.0 \mathrm{~mol} \%$ for each catalyst component (Table 3, entry 1) leading to full conversion of the substrate syn1. Under such conditions, the reaction pathway discussed above using only TBAB is slow enough to be neglected ( $c f$., Table 1 entry 1).

These conditions led to a reaction mixture from which four major cyclic carbonate products (syn-cis $\mathbf{2 B}$, syn-trans $\mathbf{3 A}$ syntrans $\mathbf{3 B}$ and anti-trans $\mathbf{4 A}$ ) could be identified. Whereas for syn-cis 2B the NMR and structural features had already been determined (see Table 1 and Figure 1), two products were unambiguously assigned by X-ray diffraction studies (Figure 3) after they had been separated by chromatography and isolated. A fourth product was produced in minor amounts and was assigned by NMR spectroscopy (see SI) as the last remaining possible $s y n$-isomer $\mathbf{3 A}$
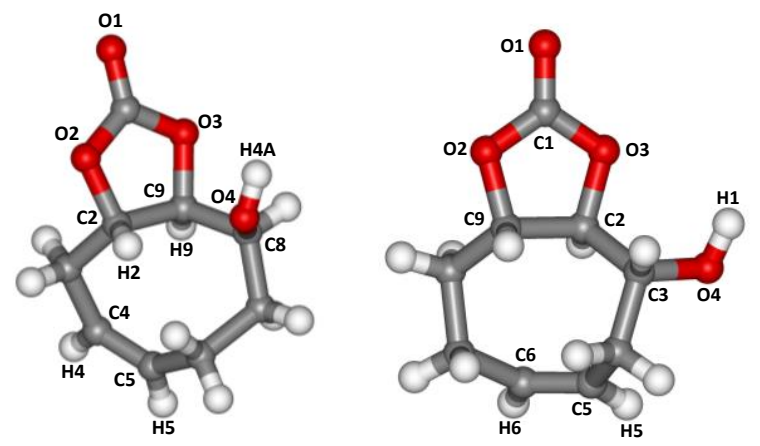

Figure 3. LEFT: X-ray molecular structure determined for syntrans 3B. Some selected pertinent bond lengths $(\AA)$ and dihedral angles $\left({ }^{\circ}\right)$ with esd's in parentheses: $\mathrm{C}(4)-\mathrm{C}(5)=1.3384(15)$; $\mathrm{O}(2)$ $\mathrm{C}(9)-\mathrm{C}(2)-\mathrm{O}(3)=4.07(9), \quad \mathrm{O}(3)-\mathrm{C}(9)-\mathrm{C}(8)-\mathrm{O}(4)=71.02(9)$. RIGHT: X-ray molecular structure determined for anti-trans 4A. Some selected pertinent bond lengths $(\AA)$ and dihedral angles $\left(^{\circ}\right)$ with esd's in parentheses: $\mathrm{C}(5)-\mathrm{C}(6)=1.329(2), \mathrm{O}(2)-\mathrm{C}(9)-\mathrm{C}(2)$ $\mathrm{O}(3)=15.56(12), \mathrm{O}(3)-\mathrm{C}(2)-\mathrm{C}(3)-\mathrm{O}(4)=-66.30(14)$.

Both carbonate structures 3B and 4A show a cyclic carbonate having a trans configuration $(c f$., relative position of $\mathrm{H} 2$ and $\mathrm{H} 9$ in syn-trans $\mathbf{3 B}$ ). The $\mathrm{OH}$ fragment in $\mathbf{3 B}$ is in a synposition to the trans-configured carbonate ring, whereas in $\mathbf{4 A}$ this position is anti. The configuration of $\mathbf{3 B}$ suggests the involvement of the alcohol group in its formation whereas the formation of $\mathbf{4 A}$ implies a different mechanism not implicating the $\mathrm{OH}$ fragment of the substrate syn-1.

With the major components now being identified, we sought to first increase the selectivity towards the syn-trans carbonate 3B (Table 2, entries 2-10). The presence of an excess (10 equiv) of TBAB with respect to $\mathrm{Al}(\mathrm{III})$ complex $\mathbf{A l}^{\mathrm{Me}}$ increased the production of 2B (likely through mechanism discussed above), but did not significantly increase the selectivity for 3B (entry 3). However, changing the Lewis acid catalyst from $\mathbf{A l}^{\mathrm{Me}}$ to $\mathbf{A l}^{\mathrm{Cl}}$ (entries 3-5) while increasing the amount of $\mathrm{Al}^{\mathrm{Cl}}$ :TBAB (ratio 1:1) to 5.0 mol\% provided syn-trans 4 with a $90 \%$ selectivity (entry 5). A further increase in the amount of catalyst (entries 6 and 7) showed no beneficial effect. The higher Lewis acidity of catalyst $\mathbf{A l}^{\mathbf{C l}}$ is likely responsible for the suppression of the formation of $\mathbf{2 B}$, whereas a higher loading of TBAB leads to suppression of $\mathbf{4 A}$. The yield of syn-trans $\mathbf{3 B}$ was then further optimized (Table 2 entries $8-10$ ) using a 1.0 mmol scale and autoclave reactors operated under the optimal conditions reported in entry 5 . Importantly, in these latter reactions the maximum yield of carbonate products was around $55 \%$ 
(with $42 \%$ being the desired syn-trans 3B) while producing significant amounts of unidentified side-products (45\%). From this reaction mixture (entry 8), pure syn-trans $\mathbf{3 B}$ was isolated in $29 \%$ after chromatographic work-up. Lowering the temperature or the pressure led to lower yields of $\mathbf{3 B}$ and an increased amount of unidentified side-products (entries $9 \& 10$ ). The rather similar $R_{\mathrm{f}}$ values for all carbonate products produced under these conditions complicated a further improvement of the isolated yield.

In order to explain the lower yield of syn-trans $\mathbf{3 B}$ as opposed to syn-cis $\mathbf{2} \mathbf{B}$, we performed several control experiments involving the substrate syn-1 and the $\mathrm{Al}(\mathrm{III})$ complex $\mathbf{A l}^{\mathrm{Cl}}$. First, heating a solution of syn-1 and an internal standard (1,3,5-trimethoxy-benzene) dissolved in MEK to $80^{\circ} \mathrm{C}$ did not result in any observable degradation of starting material after $18 \mathrm{~h}$ as monitored by ${ }^{1} \mathrm{H}$ NMR. Then the experiment was repeated with a catalytic amount of $\mathbf{A l}^{\mathbf{C l}}$ (5.0 mol\%) present. The progress of the experiment was followed by ${ }^{1} \mathrm{H}$ NMR and, with time, a gradual decrease of the original amount of $s y n-\mathbf{1}$ was noted. After $18 \mathrm{~h}, 33 \%$ of substrate was remaining while after 3 days only trace amount of syn-1 could be detected, while other possible products were not observed. The latter experiment was then repeated in $d_{8}$-toluene as medium; despite that the decrease in substrate conversion was lower, after $18 \mathrm{~h}$ only $60 \%$ of starting material was noted, and a significant amount of material precipitated from solution. Both the solution phase as well as the precipitated solid were scrutinized by ${ }^{1} \mathrm{H}$ NMR and IR analysis, but showed virtually identical results. Whereas the NMR spectra displayed broadened signals, the IR was more informative and pointed at the formation of an oligo/polyether compound. ${ }^{59}$

It appears that at elevated temperature strong Lewis acids such as $\mathbf{A l}^{\mathbf{C l}}$ are capable of inducing ring-opening of the oxirane. Recently we described similar Al(III) aminotriphenolate complexes that can activate epoxy alcohols following proton transfer to one of the phenolate donor atoms of the complex providing an Al-alkoxide species. ${ }^{53,54}$ In the absence of any reagent, this nucleophilic alkoxide should be able to engage in ring-opening of a second molecule of epoxy alcohol leading eventually to a stepwise formation of an oligoether. The formation of the latter type of byproduct from sterically more congested epoxides has precedent as was recently demonstrated by Fiorani et al. in the synthesis of terpene-based cyclic carbonates under fairly similar reaction conditions $\left(85^{\circ} \mathrm{C}, 10-40 \mathrm{bar}\right.$; using $\left.1.0 \mathrm{~mol} \% \mathrm{Al}^{\mathrm{Cl}}\right){ }^{60}$

Al-Catalyzed Formation of Anti-Trans 4A. Finally, we optimized conditions in order to selectively synthesize antitrans 4A (Table 3). Since we were able to suppress the formation of $4 \mathrm{~A}$ entirely by increasing the concentration of TBAB in Table 3, we envisioned that omitting TBAB would favor the formation of 4A. Instead, decomposition of syn-1 was observed. The addition of a base as co-catalyst proved essential in order to steer the reaction towards $\mathbf{4 A}$. Several (N-heterocyclic) bases were probed (Table 3 ), and initially 4-dimethylaminopyridine (DMAP) demonstrated a selectivity for $\mathbf{4 A}$ of $82 \%$ (entry 2). Further variation of the base (DBU, DIPEA), the Al(III) complex $\left(\mathbf{A l}^{\mathrm{Me}}\right.$ or $\left.\mathbf{A l}^{\mathrm{Cl}}\right)$ and the (relative/total) amounts of $\mathrm{Al}(\mathrm{III})$ complex and base finally gave an optimized selectivity of $86 \%$ (entry 7). Interestingly, using DIPEA we were unable to obtain any carbonate products, indicating that relatively nucleophilic bases are required for the reaction to occur.
Table 3. Optimization of the Reaction Conditions leading to Anti-Trans Carbonate (4A). ${ }^{a}$

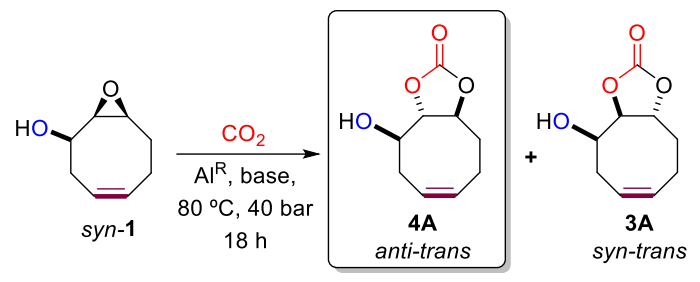

$\begin{array}{cccc}\text { entry } & \begin{array}{c}{[\mathrm{Al}]} \\ (\mathrm{mol} \%)\end{array} & \begin{array}{c}\text { Base } \\ (\mathrm{mol} \%)\end{array} & \begin{array}{c}\text { Sel. 4A:3A } \\ (\%)^{b}\end{array} \\ 1 & \mathbf{A l}^{\mathbf{M e}}, 1.0 & \text { DMAP, 10 } & 79: 21 \\ 2 & \mathbf{A l}^{\mathrm{Me}}, 5.0 & \text { DMAP, 20 } & 82: 18 \\ 3 & \mathbf{A l}^{\mathrm{Me}}, 1.0 & \text { DBU, 10 } & 79: 21 \\ 4 & \mathbf{A l}^{\mathbf{M e}}, 5.0 & \text { DBU, 5.0 } & 76: 24 \\ 5 & \mathbf{A l}^{\mathbf{M e}}, 5.0 & \text { DBU, 15 } & 82: 18 \\ 6 & \mathbf{A l}^{\mathbf{M e}}, 5.0 & \text { DBU, 20 } & 85: 15 \\ 7 & \mathbf{A l}^{\mathbf{M e}}, 5.0 & \text { DBU, 25 } & 86: 14 \\ 8 & \mathbf{A l}^{\mathbf{C l}}, 5.0 & \text { DMAP, 5.0 } & 84: 16 \\ 9 & \mathbf{A l}^{\mathbf{C l}}, 5.0 & \text { DBU, 5.0 } & 81: 19 \\ 10 & \mathbf{A l}^{\mathbf{C l}}, 5.0 & \text { DIPEA, 5.0 } & 0: 0\end{array}$

${ }^{a}$ Reaction conditions: $80{ }^{\circ} \mathrm{C}, 40$ bar $\mathrm{CO}_{2}$, syn-1 (0.5 mmol, 70 $\mathrm{mg}, 2.5 \mathrm{M}$ ), base (type and amount indicated), MEK. Conversion was quantitative in all cases. ${ }^{b}$ Based on ${ }^{1} \mathrm{H}$ NMR integration of the crude product. Carbonates $\mathbf{2 A}, \mathbf{2 B}$ and $\mathbf{3 B}$ could not be detected.

Again, the yield for anti-trans $\mathbf{4 A}$ was further maximized using larger scale experiments as reported for syn-trans $\mathbf{3 B}$ in an autoclave reactor (Table 4). The observation of substantial amounts of oligoether byproduct in the synthesis of syn-trans 3B (see Table 2) prompted us to initially use lower reaction temperatures (Table 4, entries 1-3). However, the NMR yield of anti-trans $\mathbf{4 A}$ was not positively affected and neither a change in the pressure or reaction time (in combination with a lower amount of catalyst components) gave any improvement. As expected, a lower conversion of the substrate syn-1 was noted under these latter conditions. Raising the reaction temperature to $80{ }^{\circ} \mathrm{C}$ (entry 4 ) increased the overall carbonate yield to $73 \%$ and produced anti-trans $\mathbf{4 A}$ in 59\% (NMR) yield. Further variations were probed including lowering the pressure or the loading of the catalyst components, eliminating purging of the reactor prior to pressurizing at 40 bar (to reduce possible loss of the volatile syn-1) and changing the solvent (entries 5, 6, 8 and 9). Notably, when the catalytic experiment was repeated using the conditions of entry 4 while elongating the reaction time to $48 \mathrm{~h}$, practically the same results were obtained showing the stable character of the carbonate products once formed under the experimental conditions $\left(80^{\circ} \mathrm{C}, 40 \mathrm{bar}\right.$, in the presence of $\mathbf{A l}^{\mathrm{Me}}$ and DBU). From the crude product produced in entry 7 the desired anti-trans 4A (57\% NMR yield) was isolated in $25 \%$ yield. ${ }^{61}$ The isolation and characterization of trans-fused cyclic carbonates is difficult and rare, and only few examples have been reported in the literature. ${ }^{25,62,63}$ 
Table 4. Optimization of the Yield of Anti-Trans Carbonate (4A) obtained from Syn-1. ${ }^{a}$

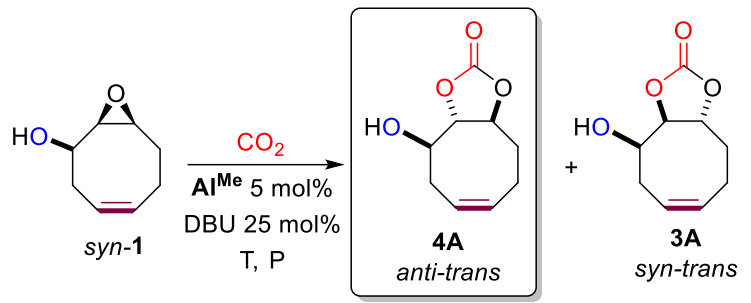

$\begin{array}{ccccccc}\text { entry } & \begin{array}{c}\mathrm{T} / \mathrm{P} \\ \left({ }^{\circ} \mathrm{C} / \mathrm{b} a r\right)\end{array} & \begin{array}{c}\mathrm{t} \\ (\mathrm{h})\end{array} & \begin{array}{c}\text { Conv. } \\ (\%)^{b}\end{array} & \begin{array}{c}\text { 4A } \\ (\%)^{b}\end{array} & \begin{array}{c}\text { 3A } \\ (\%)^{b}\end{array} & \begin{array}{c}\text { Rest } \\ (\%)^{c}\end{array} \\ 1 & 70 / 40 & 24 & >99 & 49 & 17 & 34 \\ 2 & 70 / 10 & 24 & 79 & 47 & 19 & 13 \\ 3^{e} & 70 / 40 & 18 & 89 & 45 & 22 & 22 \\ 4 & 80 / 40 & 24 & >99 & 59 & 14 & 27 \\ 5 & 80 / 10 & 24 & 94 & 47 & 14 & 33 \\ 6^{e} & 80 / 40 & 24 & >99 & 44 & 14 & 42 \\ 7 & 80 / 40 & 48 & >99 & 57(25)^{d} & 18 & 25 \\ 8^{f} & 80 / 40 & 24 & >99 & 54 & 14 & 32 \\ 9^{g} & 80 / 40 & 24 & >99 & 40 & 13 & 47\end{array}$

${ }^{a}$ Reaction conditions: autoclave reactors were used equipped with a $20 \mathrm{~mL}$ Teflon insert; temperature/pressure indicated, syn-1 (1.0 mmol, $140 \mathrm{mg}, 2.5 \mathrm{M}), \mathbf{A l}^{\mathrm{Me}}(22 \mathrm{mg}, 5 \mathrm{~mol} \%)$, DBU $(37 \mu \mathrm{L}, 25$ mol\%), 1,3,5-trimethoxy-benzene (TMB, $189.2 \mathrm{mg}, 1$ equiv), MEK. ${ }^{b}$ Determined by ${ }^{1} \mathrm{H}$ NMR $\left(\mathrm{CDCl}_{3}\right)$ using TMB as internal standard. ${ }^{c}$ Remaining mass balance of all unidentified products based on ${ }^{1} \mathrm{H} \mathrm{NMR}\left(\mathrm{CDCl}_{3}\right)$ analysis. ${ }^{d}$ In brackets, the isolated yield for $4 \mathrm{~A}$ is reported. Beside the desired product, also $16 \%$ of hydrolysed product (i.e., triol) was isolated (see the SI for details). ${ }^{e} \mathrm{Using}$ $5.0 \mathrm{~mol} \% \mathrm{DBU}$ and $1.0 \mathrm{~mol} \% \mathbf{A l}^{\mathrm{Me}}$. ${ }^{f}$ The reactor was not purged with $\mathrm{CO}_{2}$ prior to the experiment. ${ }^{g}$ Using toluene as solvent.

\section{CONCLUSIONS}

The introduction of a symmetry-breaking element (double bond) in the backbone of cyclic epoxy alcohol syn-1 allows for its conversion into various regio- and diastereo-isomeric bicyclic carbonates. The nature of the catalytic system controls the bias towards specific cyclic carbonate products with in general good selectivity for one specific carbonate of around $90 \%$. The use of TBAB as catalyst produces syn-cis $\mathbf{2 B}$ as major component under thermodynamic control, whereas combining TBAB with an $\mathrm{Al}(\mathrm{III})$ aminotriphenolate complex $\left(\mathrm{Al}^{\mathrm{Cl}}\right)$ changes the diastereoselectivity towards syn-trans 3B. The replacement of the bromide based nucleophile for an N-heterocyclic base (DBU) modifies the carbonate selectivity significantly and generates regio- and diastereomer anti-trans $\mathbf{4 A}$ as the principal carbonate product. The unusual trans configuration of both syntrans $\mathbf{3 B}$ and anti-trans $\mathbf{4 A}$ were both confirmed by X-ray crystallography and are rare examples of such types of heterocycles. We have identified 5 out of 8 isomeric bicyclic carbonate products, and we optimized the synthesis of 3 of them. Further work is now focusing on unraveling the mechanisms leading to the formation of the trans-fused bicyclic carbonates while improving the overall chemo-selectivity.

\section{EXPERIMENTAL SECTION}

General Considerations. The $\mathrm{Al}$ complexes $\mathbf{A l}^{\mathrm{Me} 47}$ and $\mathbf{A l}{ }^{\mathbf{C l} 47}$ and epoxy alcohol $\mathbf{1}^{64}$ were prepared according to previously reported procedures. Carbon dioxide was purchased from PRAXAIR and used without further purification. Solvents used in the synthesis of the complexes were dried using an Innovative Technology PURE SOLV solvent purification system. Solvents used in the catalytic screening were used as received. ${ }^{1} \mathrm{H}$ and ${ }^{13} \mathrm{C}$ and $2 \mathrm{D}$ NMR spectra were recorded on a Bruker AV-300, AV-400 or AV-500 spectrometer, and signals are referenced to the residual solvent peak. FT-IR measurements were carried out using a Bruker Optics FTIR Alpha spectrometer. Mass spectrometric analyses and X-ray diffraction analysis were performed by the Research Support Area (RSA) at ICIQ.

General Catalytic Procedure using Autoclave Reactors: The experiments reported in Table S1 (entries 1-3), Table 2 (entries 810) and Table 4 (entries 1-9) were carried out using this protocol; a photo of this reactor is reported in the SI. Typical conditions are as follows: epoxy alcohol $1(1.0 \mathrm{mmol}, 140 \mathrm{mg}, 1.0 \mathrm{M})$, TBAB $(16-82 \mathrm{mg}$, 5-25 mol\%) and $\mathrm{Al}$ complex $\mathbf{A l}^{\mathrm{Cl}}$ (note: only for Tables 2 and $3 ; 28 \mathrm{mg}$, $5.0 \mathrm{~mol} \%)$, MEK $(200 \mu \mathrm{L})$ and internal standard TMB (1,3,5-trimethoxy-benzene; $189.2 \mathrm{mg}, 1$ equiv) were charged into a stainless steel autoclave equipped with a $20 \mathrm{~mL}$ Teflon insert. After the autoclave was sealed three cycles of pressurization/depressurization were carried out. After reaching the selected reaction temperature (typically $80{ }^{\circ} \mathrm{C}$ ), the autoclave was pressurized with $\mathrm{CO}_{2}$ to the desired pressure (typically 40 bar) and left stirring. At the end of the chosen time interval, the autoclave was cooled to rt and then carefully depressurized. An aliquot of the reaction mixture was taken for analysis and the conversion/yield was determined by ${ }^{1} \mathrm{H}$ NMR spectroscopy in $\mathrm{CDCl}_{3}$ to determine conversions, selectivities and NMR yields. The desired products 2-4 were then obtained by chromatographic purification as indicated below.

General Catalytic Procedure using a HEL Multi-Reactor System: The results from Table 1 (entries 1-18), Table 2 (entries 1-7) and Table 3 (entries 1-10) have been obtained with this system. A typical procedure is as follows: epoxy alcohol 1 (70 $\mathrm{mg}, 0.50 \mathrm{mmol}, 2.5$ $\mathrm{M}$ ), Al-complex $\mathbf{A l}^{\mathrm{Cl}}$ (5.0 mol\%; only added in the experiments from Tables 3 and 4), TBAB (5.0-25 mol\%) and MEK (200 $\mu \mathrm{L})$ were added into a glass insert. The HEL system was closed and after three pressurization/depressurization cycles using 10 bar of $\mathrm{CO}_{2}$ the reactor was charged with 40 bar $\mathrm{CO}_{2}$ pressure. Then the reactor was heated to the desired temperature and the mixtures were stirred for $18 \mathrm{~h}$. Finally the HEL reactor was cooled down to rt, carefully depressurized and opened. For each of the reaction mixtures an aliquot was taken and analyzed by ${ }^{1} \mathrm{H} \mathrm{NMR}\left(\mathrm{CDCl}_{3}\right)$ to determine conversions and selectivities.

General Catalytic Procedure using an AMTEC Multi-Reactor System: The results from Table 1 (entries 19-22) were performed using this multi-reactor system. Typical set up is as follows: All the solids are weight into every steel vessel in this case TBAB (25 mol\%), then overnight leak test was carried out at 30 bar. When leak test is finished the epoxy alcohol 1 (140 mg, $1 \mathrm{mmol})$ dissolved in MEK $(500 \mu \mathrm{L})$ is carefully added and the reactors are warm up to $80{ }^{\circ} \mathrm{C}$ and finally pressurized with $\mathrm{CO}_{2}(10,20,30$ and 40 bar). After the reaction time the multi-reactor was cooled down and depressurized and an aliquot was taken and analyzed by ${ }^{1} \mathrm{H} \mathrm{NMR}\left(\mathrm{CDCl}_{3}\right)$ to determine conversions and selectivities.

Synthesis of Syn-Cis Cyclic Carbonate (2B): The below mentioned protocol refers to those used in Table S1, entry 3: a mixture of syn-epoxy alcohol 1 (140 mg, $1.0 \mathrm{mmol})$ and TBAB ( $82 \mathrm{mg}, 25 \mathrm{~mol}$ $\%$ ) dissolved in $1.0 \mathrm{~mL}$ of MEK was introduced into a $30 \mathrm{~mL}$ stainless steel reactor. After three cycles of pressurization and depressurization, the reactor was charged with 40 bar of $\mathrm{CO}_{2}$. Then the reaction mixture was heated to $80^{\circ} \mathrm{C}$ and magnetically stirred for $24 \mathrm{~h}$. Finally, the reactor was cooled down to $\mathrm{rt}$ and carefully depressurized. The crude product was purified by flash chromatography on silica gel (hexane:ethyl acetate, $2: 1 \mathrm{v} / \mathrm{v}$ ) affording the title compound $(120 \mathrm{mg}, 65 \%$ yield) as a white solid. Single crystals were obtained by recrystallization from $\mathrm{CH}_{2} \mathrm{Cl}_{2} /$ hexane at room temperature. ${ }^{1} \mathrm{H} \mathrm{NMR}(400 \mathrm{MHz}$, $\left.\mathrm{CDCl}_{3}\right): \delta=5.94(\mathrm{dtd}, J=10.3,8.0,1.0 \mathrm{~Hz}, 1 \mathrm{H}), 5.66-5.48(\mathrm{~m}, 1 \mathrm{H})$, 
4.73 (ddd, $\mathrm{J}=12.6,7.3,4.2 \mathrm{~Hz}, 1 \mathrm{H}), 4.52(\mathrm{dd}, J=7.4,1.2 \mathrm{~Hz}, 1 \mathrm{H})$, $4.36-4.30(\mathrm{~m}, 1 \mathrm{H}), 3.41-3.29(\mathrm{~m}, 1 \mathrm{H}), 2.99-2.84(\mathrm{~m}, 1 \mathrm{H}), 2.80-$ $2.68(\mathrm{~m}, 1 \mathrm{H}), 2.43(\mathrm{ddd}, \mathrm{J}=11.6,6.6,4.2 \mathrm{~Hz}, 1 \mathrm{H}), 2.16-2.05(\mathrm{~m}, 1 \mathrm{H})$, $1.96-1.86(\mathrm{~m}, 1 \mathrm{H}), 1.59-1.46(\mathrm{~m}, 1 \mathrm{H}) \mathrm{ppm} .{ }^{13} \mathrm{C} \mathrm{NMR}(126 \mathrm{MHz}$, $\left.\mathrm{CDCl}_{3}\right): \delta=155.8,135.8,123.8,84.1,80.0,72.9,33.8,26.5,19.7 \mathrm{ppm}$. IR (neat): $v=3456(\mathrm{OH}), 1758(\mathrm{C}=\mathrm{O}) \mathrm{cm}^{-1}$. HRMS $(\mathrm{ESI}+\mathrm{MeOH})$ : $\mathrm{m} / z$ calcd. for $\left[\mathrm{C}_{9} \mathrm{H}_{12} \mathrm{NaO}_{4}\right]^{+}, 207.0623$; found, 207.0628.

Synthesis of Syn-Trans Cyclic Carbonate (3B): The below mentioned protocol refers to those used in Table 2, entry 9: a mixture of syn-epoxy alcohol 1 (140 mg, $1.0 \mathrm{mmol}), \mathrm{Al}$ catalyst $\mathbf{A l}^{\mathrm{Cl}}(16 \mathrm{mg}$, $5.0 \mathrm{~mol} \%)$ and TBAB $(28 \mathrm{mg}, 5.0 \mathrm{~mol} \%)$ dissolved in MEK $(1.0 \mathrm{~mL})$ was introduced into a $30 \mathrm{~mL}$ stainless steel reactor. After three cycles of pressurization and depressurization, the reactor was charged with 40 bar of $\mathrm{CO}_{2}$. Then the reaction mixture was heated to $80^{\circ} \mathrm{C}$ and magnetically stirred for $24 \mathrm{~h}$. Finally, the reactor was cooled down to rt and carefully depressurized. Flash chromatography on silica gel (hexane:ethyl acetate, 2:1 v/v) afforded the title compound as a 91:9 mixture of syn-trans $\mathbf{3 B}$ and a minor isomer ( $78 \mathrm{mg}, 42 \%$ yield) as a white solid. Note that more extensive column purification was possible (Table 3 , entry 8 ) but due to fairly similar $R_{\mathrm{f}}$ values for the carbonate products only $29 \%$ of pure syn-trans 3 B was obtained, see the SI for details. Recrystallization from $\mathrm{CH}_{2} \mathrm{Cl}_{2} /$ hexane at room temperature afford single crystals. ${ }^{1} \mathrm{H}$ NMR $\left(400 \mathrm{MHz}, \mathrm{CDCl}_{3}\right): \delta=5.75-5.64(\mathrm{~m}, 1 \mathrm{H}), 5.54$ (ddd, $J=11.8,7.9,5.7 \mathrm{~Hz}, 1 \mathrm{H}), 5.48-5.38(\mathrm{~m}, 1 \mathrm{H}), 4.55(\mathrm{dd}, J=7.9$, $1.3 \mathrm{~Hz}, 1 \mathrm{H}), 4.30-4.21(\mathrm{~m}, 1 \mathrm{H}), 3.06-2.85(\mathrm{~m}, 1 \mathrm{H}), 2.50-2.31(\mathrm{~m}, 1 \mathrm{H})$, 2.23-2.12 (m, 1H), 2.10-1.93 (m, 2H), 1.65-1.51 (m, 1H) ppm. ${ }^{13} \mathrm{C}$ NMR (126 MHz, $\left.\mathrm{CDCl}_{3}\right): \delta=154.6,131.1,123.6,84.9,74.1,66.4$, 34.1, 32.2, $20.3 \mathrm{ppm}$. IR (neat) $v=3427(\mathrm{OH}), 1793(\mathrm{C}=\mathrm{O}) \mathrm{cm}^{-1}$ HRMS (ESI+, MeOH): $\mathrm{m} / z$ calcd. for $\left[\mathrm{C}_{9} \mathrm{H}_{12} \mathrm{NaO}_{4}\right]^{+}, 207.0630$; found, 207.0628 .

Synthesis of Anti-Trans Cyclic Carbonate (4A): The below mentioned protocol refers to those used in Table 4, entry 7: a mixture of syn-epoxy alcohol $\mathbf{1}(140 \mathrm{mg}, 1 \mathrm{mmol})$, Al catalyst $\mathbf{A l}^{\mathrm{Me}}(22 \mathrm{mg}, 5.0$ $\mathrm{mol} \%$ ) and DBU (8.0 mg, $5.0 \mathrm{~mol} \%$ ) dissolved in $1.0 \mathrm{~mL}$ of MEK was introduced into a $30 \mathrm{~mL}$ stainless steel reactor. After three cycles of pressurization and depressurization, the reactor was charged with 40 bar of $\mathrm{CO}^{2}$. Then the reaction mixture was heated to $80{ }^{\circ} \mathrm{C}$ and magnetically stirred for $24 \mathrm{~h}$. Finally, the reactor was cooled down to rt and carefully depressurized. Flash chromatography on silica gel (hexane:ethyl acetate, gradient from 2:1 to $1: 1 \mathrm{v} / \mathrm{v}$ ) afforded the title compound as a colorless oil (46 mg, 25\% yield). Crystals of $\mathbf{4 A}$ were obtained from a saturated solution in $\mathrm{CDCl}_{3} / \mathrm{Hexane}$ at $-20{ }^{\circ} \mathrm{C} .{ }^{1} \mathrm{H} \mathrm{NMR}$ $\left(500 \mathrm{MHz}, \mathrm{CDCl}_{3}\right): \delta=5.82-5.68(\mathrm{~m}, 2 \mathrm{H}), 4.50-4.38(\mathrm{~m}, 2 \mathrm{H}), 3.91-$ $3.78(\mathrm{~m}, 1 \mathrm{H}), 2.51-2.37(\mathrm{~m}, 2 \mathrm{H}), 2.37-2.28(\mathrm{~m}, 1 \mathrm{H}), 2.27-2.15(\mathrm{~m}, 2 \mathrm{H})$, $1.82-1.62(\mathrm{~m}, 1 \mathrm{H}) \mathrm{ppm} .{ }^{13} \mathrm{C} \mathrm{NMR}\left(126 \mathrm{MHz}, \mathrm{CDCl}_{3}\right): \delta=154.1,130.8$, 126.1, 86.8, 79.2, 70.9, 29.8, 29.4, $21.0 \mathrm{ppm}$. IR (neat): $v=3473(\mathrm{OH})$, $1787(\mathrm{C}=\mathrm{O}) \mathrm{cm}^{-1}$. HRMS (ESI+, $\left.\mathrm{MeOH}\right): \mathrm{m} / z$ calcd. for $\left[\mathrm{C}_{9} \mathrm{H}_{12} \mathrm{NaO}_{4}\right]^{+}$, 207.0631; found, 207.0628

X-ray Crystallographic Studies: The measured crystals of syncis $\mathbf{2 A}$, syn-cis $\mathbf{2 B}$, syn-trans $\mathbf{3 B}$ and anti-trans $\mathbf{4 A}$ were stable under atmospheric conditions; nevertheless, they were treated under inert conditions immersed in perfluoro-polyether as protecting oil for manipulation. Data Collection: measurements were made on a Bruker-Nonius diffractometer equipped with an APPEX II 4K CCD area detector, a FR591 rotating anode with $\mathrm{MoK} \alpha$ radiation, Montel mirrors and a Kryoflex low temperature device $\left(T=-173^{\circ} \mathrm{C}\right)$. Full-sphere data collection was used with $\omega$ and $\varphi$ scans. Programs used: Data collection Apex2 V2011.3 (Bruker-Nonius 2008), data reduction Saint+Version 7.60A (Bruker AXS 2008) and absorption correction SADABS V. 2008-1 (2008). Structure Solution: SHELXTL Version 6.10 (Sheldrick, 2000) was used. ${ }^{65}$ Structure Refinement: SHELXTL-97-UNIX VERSION.

\section{ASSOCIATED CONTENT}

The Supporting Information is available free of charge on the ACS Publications website at DOI: 10.1021/acs.organomet.\#\#\#.

Details of the experimental procedures, copies of NMR spectra and crystallographic information (PDF)
Cartesian coordinates of the calculated structures (XYZ), for details refer to https://doi.org/10.19061/iochem-bd-1-141.

\section{Accession Codes}

CCDC 1868678-1868679 and 1945737-1945738 contain the supplementary crystallographic data for this paper. These data can be obtained free of charge via www.ccdc.cam.ac.uk/data_request/cif, or by emailing data_request@ ccdc.cam.ac.uk, or by contacting The Cambridge Crystallographic Data Centre, 12 Union Road, Cambridge CB2 1EZ, UK; fax: +44 1223336033.

\section{AUTHOR INFORMATION}

\section{Corresponding Author}

*E-mail for AWK: $\underline{\text { akleij@iciq.es }}$

ORCID

Arjan W. Kleij: 0000-0002-7402-4764

\section{Notes}

The authors declare no competing financial interest.

\section{ACKNOWLEDGMENT}

We thank the Cerca program/Generalitat de Catalunya, ICREA, MINECO (CTQ2017-88920-P and CTQ2017-88777-R) and AGAUR (2017-SGR-232 and 2017-SGR-290) for support. CM thanks MINECO for a Severo Ochoa/FPI predoctoral fellowship and DG acknowledges AGAUR for providing a FI predoctoral fellowship, and a Marie Curie/ProBIST postdoctoral fellowship (grant agreement 754510 ) to $\mathrm{BL}$.

\section{REFERENCES}

(1) Liu, Q.; Wu, L.; Jackstell, R.; Beller, M. Using Carbon Dioxide as a Building Block in Organic Synthesis. Nat. Commun. 2015, 6, 5933.

(2) Rajjak Shaikh, R.; Pornpraprom, S.; D’Elia, V. Catalytic Strategies for the Cycloaddition of Pure, Diluted, and Waste $\mathrm{CO}_{2}$ to Epoxides under Ambient Conditions. ACS Catal. 2018, 8, 419-450.

(3) Fiorani, G.; Guo, W.; Kleij, A. W. Sustainable Conversion of Carbon Dioxide: the Advent of Organocatalysis. Green Chem. 2015 , 17, 1375-1389.

(4) Börjesson, M.; Moragas, T.; Gallego, D.; Martin, R. Metal-Catalyzed Carboxylation of Organic (Pseudo)halides with $\mathrm{CO}_{2}$. ACS Catal. 2016, 6, 6739-6749.

(5) Klankermayer, J.; Wesselbaum, S.; Beydoun, K.; Leitner, W. Selective Catalytic Synthesis Using the Combination of Carbon Dioxide and Hydrogen: Catalytic Chess at the Interface of Energy and Chemistry. Angew. Chem., Int. Ed. 2016, 55, 7296-7343.

(6) Song, Q.-W.; Zhou, Z.-H.; He, L.-N. Efficient, Selective and Sustainable Catalysis of Carbon Dioxide. Green Chem. 2017, 19, 37073728.

(7) Gui, Y.-Y.; Zhou, W.-J.; Ye, J.-H.; Yu, D.-G. Photochemical Carboxylation of Activated $\mathrm{C}(\mathrm{sp} 3)-\mathrm{H}$ Bonds with $\mathrm{CO}_{2}$. ChemSusChem 2017, 10, 1337-1340.

(8) Maeda, C.; Miyazaki, Y.; Ema, T. Recent Progress in Catalytic Conversions of Carbon Dioxide. Catal. Sci. Technol. 2014, 4, 14821497.

(9) Thenert, K.; Beydoun, K.; Wiesenthal, J.; Leitner, W.; Klankermayer, J. Ruthenium-Catalyzed Synthesis of Dialkoxymethane Ethers Utilizing Carbon Dioxide and Molecular Hydrogen. Angew. Chem., Int. Ed. 2016, 55, 12266-12269

(10) Sopeña, S.; Cozzolino, M.; Maquilón, C.; Martínez Belmonte, M.; Escudero-Adán, E. C.; Kleij, A. W. Organocatalyzed Domino [3+2] Cycloaddition/Payne-Type Rearrangement using Carbon Dioxide and Epoxy Alcohols. Angew. Chem., Int. Ed. 2018, 57, 1120311207. 
(11) Wei, J.; Ge, Q.; Yao, R.; Wen, Z.; Fang, C.; Guo, L.; Xu, H.; Sun, J. Directly Converting $\mathrm{CO}_{2}$ into a Gasoline Fuel. Nat. Commun. 2017, 8,15174 .

(12) Liu, X.-F.; Li, X.-Y.; Qiao, C.; Fu, H.-C.; He, L.-N. Betaine Catalysis for Hierarchical Reduction of $\mathrm{CO}_{2}$ with Amines and Hydrosilane To Form Formamides, Aminals, and Methylamines. Angew. Chem., Int. Ed. 2017, 56, 7425-7429.

(13) Guo, W.; González-Fabra, J.; Bandeira, N. A. G.; Bo, C.; Kleij, A. W. A New and Metal-Free Synthesis of N-Aryl Carbamates under Ambient Conditions. Angew. Chem., Int. Ed. 2015, 54, 11686-11690.

(14) Yan, S.-S.; Zhu, L.; Ye, J.-H.; Zhang, Z.; Huang, H.; Zeng, H.; Li, C.-J.; Lan, Y.; Yu, D. G. Ruthenium-Catalyzed Umpolung Carboxylation of Hydrazones with $\mathrm{CO}_{2}$. Chem. Sci. 2018, 9, 4873-4878.

(15) Ren, X.; Zheng, Z.; Zhang, L.; Wang, Z.; Xia, C.; Ding, K. Rhodium-Complex-Catalyzed Hydroformylation of Olefins with $\mathrm{CO}_{2}$ and Hydrosilane. Angew. Chem., Int. Ed. 2017, 56, 310-313.

(16) Schneidewind, J.; Adam, R.; Baumann, W.; Jackstell, R.; Beller, M. Low-Temperature Hydrogenation of Carbon Dioxide to Methanol with a Homogeneous Cobalt Catalyst. Angew. Chem., Int. Ed. 2017, 56, 1890-1893.

(17) Blondiaux, E.; Pouessel, J.; Cantat, T. Carbon Dioxide Reduction to Methylamines under Metal-Free Conditions. Angew. Chem., Int. Ed. 2014, 53, 12186-12190.

(18) Maeda, C.; Taniguchi, T.; Ogawa, K.; Ema, T. Bifunctional Catalysts Based on $m$-Phenylene-Bridged Porphyrin Dimer and Trimer Platforms: Synthesis of Cyclic Carbonates from Carbon Dioxide and Epoxides. Angew. Chem., Int. Ed. 2015, 54, 134-138.

(19) Guo, W.; Laserna, V.; Rintjema, J.; Kleij, A. W. Catalytic OnePot Oxetane to Carbamate Conversions: Formal Synthesis of Drug Relevant Molecules. Adv. Synth. Catal. 2016, 358, 1602-1607.

(20) Kielland, N.; Whiteoak, C. J.; Kleij, A. W. Stereoselective Synthesis with Carbon Dioxide. Adv. Synth. Catal. 2013, 355, 2115-2138.

(21) Vaitla, J.; Guttormsen, Y.; Mannisto, J. K.; Nova, A.; Repo, T.; Bayer, A.; Hopmann, K. H. Enantioselective Incorporation of $\mathrm{CO}_{2}$ : Status and Potential. ACS Catal. 2017, 7, 7231-7244.

(22) Gui, Y.-Y.; Hu, N.; Chen, X.-W.; Liao, L.-L.; Ju, T.; Ye, J.-H.; Zhang, Z.; Li, J.; Yu, D.-G. Highly Regio- and Enantioselective Copper-Catalyzed Reductive Hydroxymethylation of Styrenes and 1,3Dienes with $\mathrm{CO}_{2}$. J. Am. Chem. Soc. 2017, 139, 17011-17014.

(23) Pupo, G.; Properzi, R.; List, B. Asymmetric Catalysis with $\mathrm{CO}_{2}$ The Direct $\alpha$-Allylation of Ketones. Angew. Chem., Int. Ed. 2016, 55, 6099-6102.

(24) Vara, B. A.; Struble, T. J.; Wang, W.; Dobish, M. C.; Johnston, J. N. Enantioselective Small Molecule Synthesis by Carbon Dioxide Fixation using a Dual Brønsted Acid/Base Organocatalyst. J. Am. Chem. Soc. 2015, 137, 7302-7305.

(25) Laserna, V.; Martin, E.; Escudero-Adán, E. C.; Kleij, A. W. Substrate-Triggered Stereoselective Preparation of Highly Substituted Organic Carbonates. ACS Catal. 2017, 7, 5478-5482.

(26) Manjolinho, F.; Arndt, M.; Gooßen, K.; Gooßen, L. J. Catalytic $\mathrm{C}-\mathrm{H}$ Carboxylation of Terminal Alkynes with Carbon Dioxide. ACS Catal. 2012, 2, 2014-2021.

(27) Luo, J.; Larrosa, I. C-H Carboxylation of Aromatic Compounds through $\mathrm{CO}_{2}$ Fixation. ChemSusChem 2017, 10, 3317-3332.

(28) Yu, D.; Teong, S. P.; Zhang, Y. Transition Metal Complex Catalyzed Carboxylation Reactions with $\mathrm{CO}_{2}$. Coord. Chem. Rev. 2015 293-294, 279-291.

(29) Tortajada, A.; Juliá-Hernández, F.; Börjesson, M.; Moragas, T.; Martin, R. Transition-Metal-Catalyzed Carboxylation Reactions with Carbon Dioxide. Angew. Chem., Int. Ed. 2018, 49, 15948-15982. See also ref. 1.

(30) Comerford, J. W.; Ingram, I. D. V.; North, M.; Wu, X. Sustainable Metal-based Catalysts for the Synthesis of Cyclic Carbonates containing Five-membered Rings. Green Chem. 2015, 17, 1966-1987.

(31) Martín, C.; Fiorani, G.; Kleij, A. W. Recent Advances in the Catalytic Preparation of Cyclic Organic Carbonates. ACS Catal. 2015, 5, 1353-1370.

(32) Pescarmona, P. P.; Taherimehr, M. Challenges in the Catalytic Synthesis of Cyclic and Polymeric Carbonates from Epoxides and $\mathrm{CO}_{2}$. Catal. Sci. Technol. 2012, 2, 2169-2187. See also refs. 2 and 3.
(33) Kindermann, N.; Jose, T.; Kleij, A. W. Synthesis of Carbonates from Alcohols and $\mathrm{CO}_{2}$. Top. Curr. Chem. 2017, 375, 1-28.

(34) Honda, M.; Tamura, M.; Nakagawa, Y.; Tomishige, K. Catalytic $\mathrm{CO}_{2}$ Conversion to Organic Carbonates with Alcohols in Combination with Dehydration System. Catal. Sci. Technol. 2014, 4, 28302845 .

(35) Honda, M.; Tamura, M.; Nakao, K.; Suzuki, K.; Nakagawa, Y.; Tomishige, K. Direct Cyclic Carbonate Synthesis from $\mathrm{CO}_{2}$ and Diol over Carboxylation/Hydration Cascade Catalyst of $\mathrm{CeO}_{2}$ with 2-Cyanopyridine. ACS Catal. 2014, 4, 1893-1896.

(36) Stoian, D.; Medina, F.; Urakawa, A. Improving the Stability of $\mathrm{CeO}_{2}$ Catalyst by Rare Earth Metal Promotion and Molecular Insights in the Dimethyl Carbonate Synthesis from $\mathrm{CO}_{2}$ and Methanol with 2Cyanopyridine. ACS Catal. 2018, 8, 3181-3193.

(37) Riemer, D.; Hirapara, P.; Das, S. Chemoselective Synthesis of Carbamates using $\mathrm{CO}_{2}$ as Carbon Source. ChemSusChem 2016, 9 , 1916-1920.

(38) Guo, W.; Laserna, V.; Martin, E.; Escudero-Adán, E. C.; Kleij, A. W. Stereodivergent Carbamate Synthesis by Selective in Situ Trapping of Organic Carbonate Intermediates. Chem. Eur. J. 2016, 22, 1722-1727.

(39) $\mathrm{Yu}, \mathrm{B} . ; \mathrm{He}, \mathrm{L} . \mathrm{H}$. Upgrading Carbon Dioxide by Incorporation into Heterocycles. ChemSusChem 2015, 8, 52-62.

(40) D’Elia, V.; Dong, H.; Rossini, A. J.; Widdifield, C. M.; Vummaleti, S. V. C.; Minenkov, Y.; Poater, A.; Abou-Hamad, E.; Pelletier, J. D. A.; Cavallo, L.; Emsley, L.; Basset, J.-M. Cooperative Effect of Monopodal Silica-Supported Niobium Complex Pairs Enhancing Catalytic Cyclic Carbonate Production. J. Am. Chem. Soc. 2015, 137, 7728-7739.

(41) Castro-Osma, J. A.; Lamb, K. J.; North, M. Cr(salophen) Complex Catalyzed Cyclic Carbonate Synthesis at Ambient Temperature And Pressure. ACS Catal. 2016, 6, 5012-5025.

(42) Miceli, C.; Rintjema, J.; Martin, E.; Escudero-Adán, E. C.; Zonta, C.; Licini, G.; Kleij, A: W. Vanadium(V) Catalysts with High Activity for the Coupling of Epoxides and $\mathrm{CO}_{2}$ : Characterization of a Putative Catalytic Intermediate. ACS Catal. 2017, 7, 2367-2373.

(43) Della Monica, F.; Vummaleti, S. V. C.; Buonerba, A.; De Nisi, A.; Monari, M.; Milione, S.; Grassi, A.; Cavallo, L.; Capacchione, C. Coupling of Carbon Dioxide with Epoxides Efficiently Catalyzed by Thioether-Triphenolate Bimetallic Iron(III) Complexes: Catalyst Structure-Reactivity Relationship and Mechanistic DFT Study. Adv. Synth. Catal. 2016, 358, 3231-3243.

(44) Liu, Y.; Ren, W.-M.; He, K.-K.; Zhang, W.-Z.; Li, W.-B.; Wang, M.; Lu, X.-B. J. Org. Chem. 2016, 81, 8959-8966.

(45) Laserna, V.; Fiorani, G.; Whiteoak, C. J.; Martin, E.; EscuderoAdán, E. C.; Kleij, A. W. Angew. Chem., Int. Ed. 2014, 53, 10416 10419.

(46) North, M.; Pasquale, R. Mechanism of Cyclic Carbonate Synthesis from Epoxides and $\mathrm{CO}_{2}$. Angew. Chem., Int. Ed. 2009, 48, 29462948.

(47) Whiteoak, C. J.; Kielland, N.; Laserna, V.; Castro-Gómez, F.; Martin, E.; Escudero-Adán, E. C.; Bo, C.; Kleij, A. W. Highly Active Aluminium Catalysts for the Formation of Organic Carbonates from $\mathrm{CO}_{2}$ and Oxiranes. Chem. Eur. J. 2014, 20, 2264-2275.

(48) Castro-Gomez, F.; Salassa, G.; Kleij, A. W.; Bo, C. A DFT Study on the Mechanism of the Cycloaddition Reaction of $\mathrm{CO}_{2}$ to Epoxides Catalyzed by Zn(Salphen) Complexes. Chem. Eur. J. 2013, 19, 6289-6298.

(49) Alves, M.; Grignard, B.; Mereau, R.; Jerome, C.; Tassaing, T.; Detrembleur, C. Organocatalyzed Coupling of Carbon Dioxide with Epoxides for the Synthesis of Cyclic Carbonates: Catalyst Design and Mechanistic Studies. Catal. Sci. Technol. 2017, 7, 2651-2684.

(50) Maeda, C.; Shimonishi, J.; Miyazaki, R.; Hasegawa, J.-Y.; Ema, T. Highly Active and Robust Metalloporphyrin Catalysts for the Synthesis of Cyclic Carbonates from a Broad Range of Epoxides and Carbon Dioxide. Chem. Eur. J. 2016, 22, 6556-6563.

(51) Castro-Osma, J. A.; North, M.; Offermans, W. K.; Leitner, W.; Müller, T. E. Unprecedented Carbonato Intermediates in Cyclic Carbonate Synthesis Catalysed by Bimetallic Aluminium(Salen) Complexes. ChemSusChem 2016, 9, 791-794. 
(52) Sopeña, S.; Martín, E.; Escudero-Adán, E. C.; Kleij, A. W. Pushing the Limits with Squaramide-Based Organocatalysts in Cyclic Carbonate Synthesis. ACS Catal. 2017, 7, 3532-3539.

(53) Rintjema, J.; Epping, R.; Fiorani, G.; Martín, E.; EscuderoAdán, E. C.; Kleij, A. W. Substrate Controlled Product Divergence in $\mathrm{CO}_{2}$ Conversion to Heterocyclic Products. Angew. Chem. Int. Ed. 2016, 55, 3972-3976.

(54) Huang, R.; Rintjema, J.; González-Fabra, J.; Martín, E.; Escudero-Adán, E. C.; Bo, C.; Urakawa, A.; Kleij, A. W. Deciphering key intermediates in the transformation of carbon dioxide into heterocyclic products. Nat. Catal. 2019, 2, 62-70.

(55) Vadivel, S. K.; Vardarajan, S.; Duclos, R. I., Jr.; Wood, J.-A. T.; Guo, J.; Makriyannis, A. Bioorg. Med. Chem. Lett. 2007, 17, 5959-5963.

(56) Rintjema, J.; Kleij, A. W. Aluminum-Mediated Formation of Cyclic Carbonates: Benchmarking Catalytic Performance Metrics. ChemSusChem 2017, 10, 1274-1282.

(57) Under these conditions, some loss (10-15\%) of the volatile substrate $s y n-1$ was noted.

(58) Whiteoak, C. J.; Martin, E.; Escudero-Adán, E. C.; Kleij, A. W. Stereochemical Divergence in the Formation of Organic Carbonates Derived from Internal Epoxides. Adv. Synth. Catal. 2013, 355, 22332239.

(59) The IR traces were compared against known poly(cyclohexene)oxide, see the SI for more details.

(60) Fiorani, G.; Stuck, M.; Martín, C.; Martínez-Belmonte, M.; Martin, E.; Escudero-Adán, E. C.; Kleij, A. W. Catalytic Coupling of Carbon Dioxide with Terpene Scaffolds: Access to Challenging BioBased Organic Carbonates. ChemSusChem 2016, 9, 1304-1311.

(61) The isolation of a triol product (16\%, see SI) clearly demonstrates a lower stability of the carbonate anti-trans $\mathbf{4 A}$ under the chromatographic conditions. The lower stability of trans versus cis cyclic carbonates has been pointed out by others, see: Tezuka, K.; Komatsu, K.; Haba, O. The Anionic Ring-Opening Polymerization of FiveMembered Cyclic Carbonates fused to the Cyclohexane Ring. Polym. J. 2013, 45, 1183-1187.

(62) McGuire, T. M.; López-Vidal, E. M.; Gregory, G. L.; Buchard, A. Synthesis of 5- to 8-membered Cyclic Carbonates from Diols and $\mathrm{CO}_{2}$ : A One-Step, Atmospheric Pressure and Ambient Temperature Procedure. J. $\mathrm{CO}_{2}$ Util. 2018, 27, 283-288.

(63) Gregory, G. L.; Jenisch, L. M.; Charles, B., Kociok-Köhn, G.; Buchard, A. Polymers from Sugars and $\mathrm{CO}_{2}$ : Synthesis and Polymerization of a $D$-Mannose-Based Cyclic Carbonate. Macromolecules 2016, 49, 7165-7169.

(64) Itoh, T.; Jitsukawa, K.; Kaneda, K.; Teranishi, S. VanadiumCatalyzed Epoxidation of Cyclic Allylic Alcohols. Stereoselectivity and Stereocontrol Mechanism. J. Am. Chem. Soc. 1978, 100, 159-169.

(65) G. M. Sheldrick, SHELXTL Crystallographic System, version 6.10; Bruker AXS, Inc.: Madison, WI, 2000. 


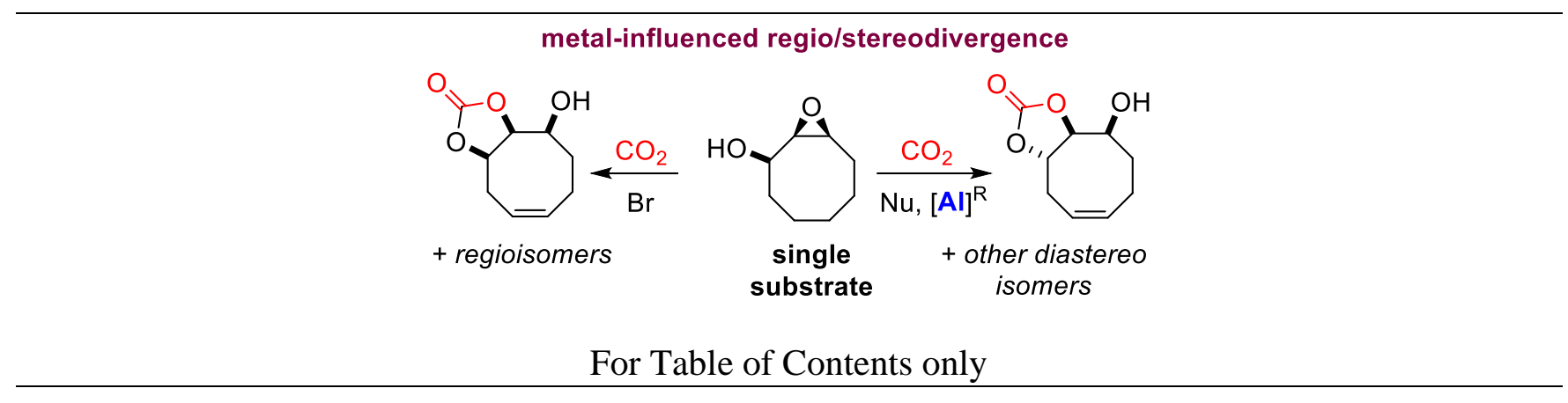

